\title{
A Scientometric Assessment of Indian Publications on Vitamin D Deficiency during 2006-15
}

\author{
Ritu Gupta', B. M. Gupta ${ }^{2}$, Kiran Baidwani ${ }^{3}$ and Jeevanjyot Kaur ${ }^{3}$ \\ 'Department of Library \& Information Science, Sri Venkateswara University, Tirupati-517502, INDIA. \\ ${ }^{2}$ Formely with CSIR-NISTADS, New Delhi, 1173, Sector-15, Panchkula-134 113, Haryana, INDIA. \\ ${ }^{3}$ Department of Dr. Tulsi Das Library, Postgraduate Institute of Medical Education \& Research Library, Chandigarh, INDIA.
}

\begin{abstract}
The present study examines 536 Indian publications on "Vitamin D Deficiency" as covered in Scopus database during 2006-15, experiencing an annual average growth rate of $37.08 \%$, citation impact per paper of 8.30 and international collaborative publication share of $15.30 \%$. The global publications share on "Vitamin D Deficiency" came from several countries, of which the top 10 most productive countries accounted for $73.67 \%$ share of global publications and $99.22 \%$ share of global citations during 2006-15. A large number of Indian organizations and authors participated in Indian research on "Vitamin D Deficiency" during 2006-15, of which the top 15 organizations and 15 authors contributed $47.57 \%$ and $33.02 \%$ publications share and $71.45 \%$ and $69.59 \%$ citation share respectively of the Indian output and citations. Medicine, among subjects, contributed the largest publications share of $88.62 \%$, followed biochemistry, genetics \& molecular biology $(22.01 \%)$, pharmacology, toxicology \& pharmaceutics $(6.53 \%)$, nursing $(6.34 \%)$ neurosciences $(2.80 \%)$, agricultural \& biological science $(2.05 \%)$ and immunology \& microbiology (1.68\%) during 2006-15. Of the total Indian publications, 530 appeared in several journals, of which the
\end{abstract}

top 15 journals contributed $31.72 \%$ share of the India's output. The top 13 highly cited papers registered 50 to 479 citations, and together contributed 1535 citations, leading to the average citation per paper of 118.08. Concludes that there is an urgent need to frame a national policy in this area, undertake more $R \& D$ and recognize vitamin $D$ deficiency as a public health problem and allocate more healthcare funds in this area.

Key words: Vitamin D deficiency, India, Publications, Scientometrics, Bibliometrics.

Correspondence :

B. M. Gupta,

Formely with CSIR-NISTADS, New Delhi, 1173

Sector-15, Panchkula-134 113, Haryana, INDIA.

Phone no: 9722563995

E-mail: bmgupta1@gmail.com

DOI: 10.5530/jyp.2016.4.3

\section{INTRODUCTION}

Vitamin D deficiency is the most under-diagnosed and under-treated nutritional deficiency in the world and widespread in individuals irrespective of their age, gender, race and geography. Vitamin D is photosynthesized in the skin on exposure to UVB rays.

Vitamin D deficiency prevails in epidemic proportions all over the Indian subcontinent, with a prevalence of $70 \%-100 \%$ in the general population. In India, widely consumed food items such as dairy products are rarely fortified with vitamin $\mathrm{D}$. Indian socio-religious and cultural practices do not facilitate adequate sun exposure, thereby negating potential benefits of plentiful sunshine. Consequently, subclinical vitamin D deficiency is highly prevalent in both urban and rural settings, and across all socioeconomic and geographic strata. ${ }^{1}$

Vitamin D deficiency has a bearing not only on skeletal but also on extra-skeletal diseases. Vitamin D deficiency is likely to play an important role in the very high prevalence of rickets, osteoporosis, cardiovascular diseases, diabetes, cancer and infections such as tuberculosis in India. Under skeleton health, chronic vitamin D deficiency in adults results in osteomalacia, osteoporosis, muscle weakness and increased risk of falls. Under extra-Skelton effects, biochemical studies have implicated vitamin $\mathrm{D}$ deficiency in many chronic diseases including, but not limited to, infectious diseases, autoimmune diseases, cardiovascular diseases, diabetes and cancer. ${ }^{1}$

The epidemic of vitamin D deficiency in India is likely to significantly contribute to the enormous burden on the healthcare system of India. Cultural and social taboos often dictate lifestyle patterns such as clothing that may limit sun exposure and vegetarianism which certainly limits vitamin D rich dietary options. Most Indians are vegetarians. The socioeconomically backward people constitute a large percentage of the population in India. The underprivileged generally suffer from overall poor nutrition. Vitamin D rich dietary sources are limited and unaffordable to most Indians. Vitamin D supplements are available, but most Indians are not aware that they need additional vitamin D. Additionally, the cost of these supplements is essentially prohibitive to the majority. Fortification of staple foods with vitamin $\mathrm{D}$ is the most viable population based strategy to achieve vitamin $\mathrm{D}$ sufficiency. ${ }^{1}$

\section{LITERATURE REVIEW}

There is no specific study focusing on bibliometric analysis of Vitamin D Deficiency literature both at national and international level. We present here some of the related bibliometric studies. Among such studies, Hari Kumar, Aravinda and Kalra ${ }^{2}$ analyzed the characteristics of all articles (1160) published by endocrinologists from India in PubMed indexed journals during 2001-12, with a focus on the type of gland and institutional affiliation. Pancreas and diabetes $(25 \%)$ lead the sub-specialty, followed by bone (19\%) and pituitary (16\%) disorders. Delhi (18\%), Chandigarh (13\%) and Lucknow (10\%) were the top locations contributing to the output. Indian Journal of Endocrinology \& Metabolism (24\%) and Journal of Association of Physicians of India (6\%) contributed the largest contributions. Bhutani, Kausal and Godara ${ }^{3}$ analyzed the publications covered in Indian Journal of Endocrinology and Metabolism (IJEM) during 2011-12. The articles were broadly divided into nine major groups consisting of pituitary, thyroid, parathyroid, pancreas and metabolic disorders, gonads, renal, and adrenal endocrinology and general endocrinology. Kumar and Aravinda ${ }^{4}$ assessed the publishing trends and the research productivity of endocrinology related research articles (2977) published in the Journal of the Association of Physicians of India (JAPI) during 2000-2011. The articles were analyzed for the type (original article, case reports, correspondence, and pictorial image), sub-specialty (diabetes, thyroid, etc.), and place of the research. Out of a total 2977 articles published by JAPI, 312 articles belong to endocrine 
sub-specialty. Endocrinology related articles constitute about $11.2 \%$ to $23.2 \%$ of the published articles per year in JAPI and the percentage is increasing every year. Diabetes (57\%) and metabolic bone disorders (16\%) lead the sub-specialty articles, followed by thyroid (9\%), adrenal and gonad (8\%), and pituitary (8\%). Chennai (20\%), Mumbai (14\%), and Delhi (9\%) are the top 3 places contributing to the articles followed by Chandigarh and Varanasi. Bharadwaj and $\mathrm{Ram}^{5}$ analyzed Indian osteoporosis literature during 1973-2012, with focus on growth of literature, extent and nature of collaboration, most productive organizations, authors and journals.

\section{OBJECTIVES}

The main objectives of this study are to study the performance of Indian research on "Vitamin D Deficiency" during 2006-15, based on publications output, as indexed in Scopus database. In particular, the study focuses on the following objectives: (i) To study the growth of world and Indian research output and its distribution by type of publication; (ii) To study the contribution \& citation impact of top 10 most productive countries; (iii) To study the share of international collaboration publications in India's output and share of leading collaborative countries; (iv) To study the distribution of Indian research output by broad subject areas; (v) To study the publication productivity and citation impact of leading Indian organizations and authors; and (vi) To study the leading media of communication and the characteristics of high cited papers.

\section{METHODOLOGY}

The study retrieved and downloaded the publication data of the world and of 10 most productive countries (including India) on "Vitamin D Deficiency" from the Scopus international multidisciplinary bibliographical and citation database (http://www.scopus.com) for 10 years during 2006-15. The keywords "Vitamin D Deficiency" was used in "Abstract, Title and Keyword" tag and restricting it to the period 2006-15 in "date range tag" was used for searching the global publication data and this become the main search string. When the main search string with restricted to 10 most productive countries in "country tag", as shown below for India below, the publication data on 10 most productive countries were obtained. When the main search string is further restricted to "subject area tag", "country tag", "source title tag", "journal title name" and "affiliation tag", we got information on distribution of publications by subject, collaborating countries, organization-wise and journal-wise, etc. For citation data, open citation window is used, where citations are counted from the date of publication till 10 February 2016.

(TITLE-ABS-KEY (VITAMIN D DEFICIENCY) AND AFFILCOUNTRY (India))

\section{ANALYSIS}

\section{Global Output and Share of Top 10 Most Productive Countries}

The top 10 most productive countries on "Vitamin D Deficiency" contributed global publication share from $2.88 \%$ to $31.81 \%$, with highest publication share coming from USA (31.81\%), followed by U.K. (8.95\%), Italy (5.10\%), Australia, Germany, Canada and France (from $4.18 \%$ to $4.94 \%$ ), Spain, India and Turkey (from $2.88 \%$ to $3.47 \%$ ) during 2006-15. The global publication share increased by $1.79 \%$ in Turkey, followed by India (1.15\%), Spain (0.68\%), Australia ().17\%), Germany (0.13\%), as against decrease by $6.74 \%$ in USA, followed by Italy (1.23\%), U.K. $(0.43 \%)$, Canada (0.37\%) and France (0.18\%) from 2006-10 to 2011-15 (Table 1). In terms of average citation per paper (ACPP), Canada achieved the highest impact (28.91), followed by USA (24.28), U.K. (20.40), Australia (20.26), Germany (19.82), France (15.32), Italy (14.80), Spain (12.25),
India (8.23) and Turkey (5.73) during 2006-15. The first 6 countries reported above average ACPP. In terms of relative citation Index, only five countries achieved above the value 1: Canada (1.91), USA (1.61), U.K (1.35), Australia (1.34), Germany (1.31) and France (1.01) during 2006-15. Canada registered the highest share (48.15\%) in terms of international collaborative papers among top 10 most productive countries, followed by Germany (39.39\%), U.K. (38.74\%), France (34.72\%), Italy (31.02\%), Australia (30.38\%), Spain (24.39\%), USA (21.46\%), India (15.67\%) and Turkey (9.38\%) during 2006-15. USA registered the highest share $(40.24 \%)$ of high cited papers among top 10 most productive countries, followed by U.K. (18.34\%), Canada (10.95\%), Germany (7.69\%), Italy (7.40\%), Australia (7.10\%), France (4.14\%), Spain (2.96\%), India and Turkey (0.59\% each) during 2006-15 (Table 2).

\section{Indian Publication Output on "Vitamin D Deficiency}

The world and Indian output on "Vitamin D Deficiency" consisted of 16672 and 536 publications during 2006-15, which increased from 807 and 10 publications in 2006 to 2098 and 103 publications in 2015, witnessing annual average growth rates of $11.83 \%$ and $37.08 \%$ during 2006-15. The cumulative global and Indian publications on "Vitamin D Deficiency" increased from 5699 and 140 during 2006-10 to 10973 and 396 during 2011-15, registering growth rates of $92.54 \%$ and $182.86 \%$ (Table 3). Of the total Indian publications, $68.10 \%$ (365) appeared as journal articles, $12.87 \%(69)$ as reviews, $8.77 \%(47)$ as letters, $4.66 \%$ (25) as editorials, $1.87 \%(10)$ as notes, $1.49 \%(8)$ as conference papers, $1.12 \%(6)$ as articles in press, 0.56 (3) book chapters, $0.37 \%$ (2) as short surveys and $0.19 \%$ (1) as book during 2006-15. India's global publication share on "Vitamin D Deficiency" was 3.21\%, which increased from $2.46 \%$ to $3.61 \%$ from $2006-10$ to $2011-15$. The average citation per paper registered by global and Indian publications on "Vitamin D Deficiency" were 15.13 and 8.30 , decreasing from 28.35 to 8.10 in global publications and 20.99 to 3.71 in Indian publications from 2006-10 to 2011-15. India's international collaborative publication share on "Vitamin D Deficiency" was $15.30 \%$ during $2006-15$, which increased from $15.0 \%$ to $15.40 \%$ from 2006-10 to 2011-15 (Table 3). The largest collaborative publication share $(39.02 \%)$ by foreign collaborative countries in India's output on "Vitamin D Deficiency" came from U.K., followed by USA (34.15\%), Australia and Canada (13.41\% each), Switzerland and South Africa ( $8.54 \%$ each), Germany (7.32\%), etc. The international collaborative publication share increased by $9.84 \%$ in Germany, followed by USA (7.49\%), Saudi Arabia (6.56\%), Australia and Canada (5.23\% each), as against decrease in $11.55 \%$ in U.K., South Africa (7.73\%), Netherland (6.25\%) and Switzerland (1.33\%) from 2006-10 to 2011-15 (Table 4).

\section{Citations Distribution}

Of the total publications (536) on "Vitamin D Deficiency", 66.87\% (337) were cited 1 or more times during 2006-15. Of the total cited publications, top $0.37 \%$ (2) publications (received citations .100 citations) contributed $16.21 \%$ citation share, top $2.24 \%$ (12) publications (received citations from 51 to 100 ) contributed $33.44 \%$ citation share, top $6.16 \%$ (33) publications (received citations 31 or more) contributed $52.33 \%$ citations share, top 19.22\% (103) publications (received 11 or more citations) contributed $80.02 \%$ citation share and top $62.88 \%$ (337) publications (received citations 1 or more citations) contributed $100.00 \%$ citations share during 2006-15 (Table 5).

\section{Subject-Wise Distribution of Publications}

The publications output was classified according to Scopus bibliographical database classification. The largest share of publications $(88.62 \%)$ was classified under medicine, followed by biochemistry, genetics \& molecular biology (22.01\%), pharmacology, toxicology \& pharmaceutics (6.53\%), 
Table 1: Contribution and Global Publication Share of Top 10 Most Productive Countries on “Vitamin D Deficiency" during 2006-15

\begin{tabular}{ccccccc}
\hline Name of the Country & \multicolumn{3}{c}{ Number of Publications } & \multicolumn{3}{c}{ Publication Share } \\
\cline { 2 - 7 } & $2006-10$ & $2011-15$ & $2006-15$ & $2006-10$ & $2011-15$ & $2006-15$ \\
\hline United States & 2066 & 3238 & 5304 & 36.25 & 29.51 & 31.81 \\
United Kingdom & 526 & 966 & 1492 & 9.23 & 8.80 & 8.95 \\
Italy & 337 & 514 & 851 & 5.91 & 4.68 & 5.10 \\
Australia & 275 & 548 & 823 & 4.83 & 4.99 & 4.94 \\
Germany & 266 & 526 & 792 & 4.67 & 4.79 & 4.75 \\
Canada & 263 & 466 & 729 & 4.61 & 4.25 & 4.37 \\
France & 245 & 452 & 697 & 4.30 & 4.12 & 4.18 \\
Spain & 172 & 406 & 578 & 3.02 & 3.70 & 3.47 \\
India & 140 & 396 & 536 & 2.46 & 3.61 & 3.21 \\
Turkey & 97 & 383 & 480 & 1.70 & 3.49 & 2.88
\end{tabular}

Table 2: Contribution, Citation Impact and International Collaborative Publication Share of Top 10 Most Productive Countries on "Vitamin D Deficiency" during 2006-15

\begin{tabular}{ccccccccccccc}
\hline $\begin{array}{c}\text { Name of the } \\
\text { Country }\end{array}$ & TP & TC & ACPP & GPS & GCS & RCI & HI & ICP & \%ICP & HCP & $\% H C P$ \\
\hline United States & 5304 & 128803 & 24.28 & 31.81 & 51.08 & 1.61 & 136 & 1138 & 21.46 & 136 & 40.24 \\
United Kingdom & 1492 & 30442 & 20.40 & 8.95 & 12.07 & 1.35 & 81 & 578 & 38.74 & 62 & 18.34 \\
Italy & 851 & 12598 & 14.80 & 5.10 & 5.00 & 0.98 & 53 & 264 & 31.02 & 25 & 7.40 \\
Australia & 823 & 16674 & 20.26 & 4.94 & 6.61 & 1.34 & 62 & 250 & 30.38 & 24 & 7.10 \\
Germany & 792 & 15700 & 19.82 & 4.75 & 6.23 & 1.31 & 64 & 312 & 39.39 & 26 & 7.69 \\
Canada & 729 & 21072 & 28.91 & 4.37 & 8.36 & 1.91 & 65 & 351 & 48.15 & 37 & 10.95 \\
France & 697 & 10681 & 15.32 & 4.18 & 4.24 & 1.01 & 52 & 242 & 34.72 & 14 & 4.14 \\
Spain & 578 & 7079 & 12.25 & 3.47 & 2.81 & 0.81 & 42 & 141 & 24.39 & 10 & 2.96 \\
India & 536 & 4410 & 8.23 & 3.21 & 1.75 & 0.54 & 32 & 84 & 15.67 & 2 & 0.59 \\
Turkey & 480 & 2748 & 5.73 & 2.88 & 1.09 & 0.38 & 26 & 45 & 9.38 & 2 & 0.59 \\
World & 16672 & 252178 & 15.13 & 100.00 & 100.00 & 1.00 & 61.3 & 3405 & 20.42 & 338 & 100.00 \\
\hline
\end{tabular}

$\mathrm{TP}=$ Total Papers; TC=Total Citations; ACPP=Average Citation Per Paper; GPS=Global Publication Share; GCS=Global Citation Share; HI=h-index; ICP=International Collaborative Papers; HCP=High Cited Papers.

Table 3: Global and Indian Publications on “Vitamin D Deficiency" during 2006-15

\begin{tabular}{cccccccccc}
\hline \multirow{2}{*}{$\begin{array}{c}\text { Publication } \\
\text { Year }\end{array}$} & TP & TC & ACPP & TP & TC & ACPP & ICP & \%ICP & \%TP \\
\cline { 2 - 10 }$y$ & 26035 & 32.26 & 10 & 289 & 28.9 & 1 & 10 & 1.24 \\
2007 & 896 & 34786 & 38.82 & 15 & 331 & 22.07 & 3 & 20 & 1.67 \\
2008 & 1131 & 37586 & 33.23 & 40 & 682 & 17.05 & 5 & 12.5 & 3.54 \\
2009 & 1270 & 30304 & 23.86 & 30 & 1058 & 35.27 & 4 & 13.33 & 2.36 \\
2010 & 1595 & 34552 & 21.66 & 45 & 579 & 12.87 & 8 & 17.78 & 2.82 \\
2011 & 1958 & 34452 & 17.60 & 54 & 395 & 7.31 & 9 & 16.67 & 2.76 \\
2012 & 2252 & 26489 & 11.76 & 66 & 443 & 6.71 & 15 & 22.73 & 2.93 \\
2013 & 2402 & 18447 & 7.68 & 86 & 290 & 3.37 & 15 & 17.44 & 3.58 \\
2014 & 2263 & 8209 & 3.63 & 87 & 297 & 3.41 & 7 & 8.05 & 3.84 \\
2015 & 2098 & 1328 & 0.63 & 103 & 46 & 0.45 & 15 & 14.56 & 4.91 \\
$2006-10$ & 5699 & 163263 & 28.65 & 140 & 2939 & 20.99 & 21 & 15.00 & 2.46 \\
$2011-15$ & 10973 & 88925 & 8.10 & 396 & 1471 & 3.71 & 61 & 15.40 & 3.61 \\
$2006-15$ & 16672 & 252188 & 15.13 & 536 & 4410 & 8.23 & 82 & 15.30 & 3.21 \\
\hline
\end{tabular}

TP=Total Papers; TC=Total Citations; ACPP=Average Citation Per Paper; ICP=International Collaborative Papers. 
Table 4: Share of Leading Foreign Collaborative Countries in India's Output on “Vitamin D Deficiency" during 2006-15

\begin{tabular}{ccccccc}
\hline $\begin{array}{c}\text { Collaborative } \\
\text { Country }\end{array}$ & \multicolumn{3}{c}{$\begin{array}{c}\text { No. of International } \\
\text { Collaborative Papers }\end{array}$} & \multicolumn{2}{c}{ Share of International Collaborative } \\
Papers
\end{tabular}

Table 5: Distribution of Citations by Publications on "Vitamin D Deficiency" during 2006-15

\begin{tabular}{ccccc}
\hline Citation Range & $\begin{array}{c}\text { No. of } \\
\text { Papers }\end{array}$ & $\begin{array}{c}\text { No. of } \\
\text { Citations }\end{array}$ & $\begin{array}{c}\text { Share of } \\
\text { Papers }\end{array}$ & $\begin{array}{c}\text { Share of } \\
\text { Citations }\end{array}$ \\
\hline 0 & 199 & 0 & 37.13 & 0 \\
$1-10$ & 234 & 881 & 43.66 & 19.98 \\
$11-30$ & 70 & 1221 & 13.06 & 27.69 \\
$51-50$ & 21 & 833 & 3.92 & 18.89 \\
$>100$ & 10 & 760 & 1.87 & 17.23 \\
& 2 & 715 & 0.37 & 16.21 \\
& 536 & 4410 & 100.00 & 100 \\
\hline
\end{tabular}

Table 6: Subject-Wise Distribution of Publications on "Vitamin D Deficiency": 2006-15

\begin{tabular}{|c|c|c|c|c|c|c|c|c|c|}
\hline \multirow[t]{2}{*}{ Name of the Subject } & \multicolumn{3}{|c|}{ No. of Papers } & \multicolumn{3}{|c|}{ Share of Papers } & \multirow[t]{2}{*}{ TC } & \multirow[t]{2}{*}{ ACPP } & \multirow[t]{2}{*}{$\mathrm{HI}$} \\
\hline & 2006-10 & 2010-15 & 2006-15 & 2006-10 & 2010-15 & 2006-15 & & & \\
\hline Medicine & 122 & 353 & 475 & 87.14 & 89.14 & 88.62 & 3855 & 8.12 & 29 \\
\hline Biochemistry, genetics \& molecular biology & 26 & 92 & 118 & 18.57 & 23.23 & 22.01 & 814 & 6.90 & 16 \\
\hline Pharmacology, toxicology \& pharmaceutics & 5 & 30 & 35 & 3.57 & 7.58 & 6.53 & 192 & 5.49 & 6 \\
\hline Nursing & 8 & 26 & 34 & 5.71 & 6.57 & 6.34 & 385 & 11.32 & 10 \\
\hline Neuroscience & 5 & 10 & 15 & 3.57 & 2.53 & 2.80 & 60 & 4.00 & 4 \\
\hline Agricultural \& biological science & 5 & 6 & 11 & 3.57 & 1.52 & 2.05 & 300 & 27.27 & 6 \\
\hline Immunology \& microbiology & 0 & 9 & 9 & 0.00 & 2.27 & 1.68 & 59 & 6.56 & 5 \\
\hline Total of India & 140 & 396 & 536 & & & & & & \\
\hline
\end{tabular}

TC=Total Citations; $\mathrm{ACPP}=$ Average Citation Per Paper; $\mathrm{HI}=\mathrm{h}$-index.

nursing $(6.34 \%)$ neurosciences $(2.80 \%)$, agricultural \& biological science (2.05\%) and immunology \& microbiology (1.68\%) during 2006-15. The publication activity has increased in medicine (from $87.14 \%$ to $89.14 \%$ ), biochemistry, genetics \& molecular biology (from $18.57 \%$ to $23.23 \%$ ), pharmacology, toxicology \& pharmaceutics (from $3.57 \%$ to $7.58 \%$ ), nursing (from $5.71 \%$ to $6.57 \%$ ) and immunology \& microbiology (from $0.0 \%$ to $2.27 \%$, as against decrease in neuroscience (from $3.57 \%$ to $2.53 \%$ ) and agricultural \& biological sciences (from $3.57 \%$ to $1.52 \%$ ) from $2006-10$ to 2011-15. Agricultural \& biological sciences registered the highest citation impact per paper (27.27), followed by nursing (11.32), medicine (8.12), biochemistry, genetics \& molecular biology (6.90), immunology \& microbiology (6.56) pharmacology, toxicology \& pharmaceutics (5.49) and nursing (4.0) during 2006-15 (Table 6).

\section{Contribution and Citation Impact of Most Productive Organizations}

The top 15 organizations on "Vitamin D Deficiency" individually contributed 8 to 63 publications and together they contributed 255 publi- 
Gupta et al.: A Scientometric Assessment of Indian Publications on Vitamin D Deficiency

Table 7: Profile of Top 15 Most Productive Organizations on “Vitamin D Deficiency" during 2006-15

\begin{tabular}{|c|c|c|c|c|c|c|}
\hline Name of the Organization & TP & TC & ACPP & $\mathrm{HI}$ & ICP & \%ICP \\
\hline All India Institute of Medical Sciences (AIIMS), New Delhi & 63 & 789 & 12.52 & 17 & 10 & 15.87 \\
\hline Postgraduate Institute of Medical Sciences (PGIMER), Chandigarh & 26 & 120 & 4.62 & 6 & 4 & 15.38 \\
\hline Christian Medical College (CMC), Vellore & 26 & 169 & 6.50 & 7 & 2 & 7.69 \\
\hline Sanjay Gandhi Postgraduate Institute of Medical Sciences (SGPGIMS), Lucknow & 24 & 224 & 9.33 & 8 & 1 & 4.17 \\
\hline Jehangir Hospital, Pune & 19 & 129 & 6.79 & 8 & 12 & 63.16 \\
\hline Institute of Nuclear Medicine \& Allied Sciences (INMAS), New Delhi & 13 & 223 & 17.15 & 8 & 1 & 7.69 \\
\hline Institute of Post Graduate Medical Education \& Research (IPGMER), Kolkata & 11 & 36 & 3.27 & 4 & 0 & 0.00 \\
\hline King Edward Memorial Hospital (KEMH), Mumbai & 10 & 120 & 12.00 & 6 & 2 & 20.00 \\
\hline National Institute of Nutrition (NIN), Hyderabad & 10 & 44 & 4.40 & 3 & 2 & 20.00 \\
\hline Indraprastha Apollo Hospital (IAH), Delhi & 9 & 794 & 88.22 & 5 & 2 & 22.22 \\
\hline Maulana Azad Medical College (MAMC), Delhi & 9 & 59 & 6.56 & 3 & 1 & 11.11 \\
\hline C S M Medical University, Lucknow & 9 & 164 & 18.22 & 6 & 2 & 22.22 \\
\hline Sant Parmanand Hospital, Delhi & 9 & 11 & 1.22 & 2 & 0 & 0.00 \\
\hline Sri Venkateshwara Institute of Medical Sciences, Lucknow & 9 & 247 & 27.44 & 7 & 1 & 11.11 \\
\hline Jawarharlal Nehru Medical College, Agra & 8 & 22 & 2.75 & 3 & 0 & 0.00 \\
\hline Total of 15 organizations & 255 & 3151 & 12.36 & 6.2 & 40 & 15.69 \\
\hline Total of India & 536 & 4410 & & & & \\
\hline Share of 15 organizations in India's total output & 47.57 & 71.45 & & & & \\
\hline
\end{tabular}

$\mathrm{TP}=$ Total Papers; TC=Total Citations; ACPP=Average Citation Per Paper; ICP=International Collaborative Papers; HI=h-index.

cations (47.57\% publications share) which accounted for 3151 citations (71.45\% citation share) during 2006-15. A scientometric profile of top 15 most productive organizations is shown in Table 7. Five organizations contributed more than the average productivity per paper (17.0) of all organizations: AIIMS-New Delhi (63 papers), PGIMER-Chandigarh and CMC-Vellore (26 papers each), SGPGIMS - Lucknow (24 papers) and Jehangir Hospital-Pune (19 papers) during 2006-15. Five organizations received more than the average citations per paper (12.26) of all organizations: IAH - Delhi (88.22), SVIMS - Tirupati (27.44), CSM Medical Univ - Lucknow (18.22), INMAS-Delhi (17.15) and AIIMS - New Delhi (12.52) during 2006-15. Six organizations received more than the average h-index (6.2) of all organizations: AIIMS - New Delhi (17), INMAS Delhi, SGPGIMS - Lucknow and Jehangir Hospital - Pune (8 each) and CMC - Vellore (7) during 2006-15.Six organizations registered more than average share (15.69\%) of international collaborative papers of all organizations: Jehangir Hospital - Pune (63.16\%), CSM Medical University - Lucknow and IAH-Delhi (22.22\% each), KEMH -Mumbai and NIN - Hyderabad (20.0\% each) and AIIMS-New Delhi (15.87\%) during 2006-15.

\section{Contribution and Citation Impact of Top 15 Authors}

The contribution of 15 top authors varied from 7 to 26 publications and together they contributed 177 publications (33.02\% publication share) and accounted for 3069 citations (69.59\% citation share) during 2006-15. A scientometric profile of top 15 most productive authors is shown in Table 8. Six authors published more than the average productivity per paper (11.8) of all authors: N. Gupta (26 papers), A.V. Khadikar (19 papers), R.K. Marwah (17 papers), R. Goswami (14 papers), N. Tandon (13 papers) and V. Sreenivas (12 papers) during 2006-15. Four authors registered more than the average citation per paper (17.34) of all authors: A. Mithal (88.0), N. Tandon (25.62), C,V. Harinaryan (25.10) and R. Goswami (22.0) during 2006-15, Eight authors have registered more than the average h-index (6.0) of all authors: N. Gupta (10), N. Tandon, R. Goswami and R.K. Marwah (9 each), A.V. Khadikar (8), A. Mithal, C, V. Harinaryan and V. Sreenivas (7 each) during 2006-15. Four authors registered more than the average share $(15.82 \%)$ of international collaborative papers of all authors: A.V. Khadikar (63.16\%), A. Mithal (40.0\%), S K. Bhadada (28.57\%) and N. Gupta (19.23\%) during 2006-15.

\section{Medium of Communication}

Of the 536 Indian publications on "Vitamin D Deficiency", 530 publications appeared in journals, 3 as books, 2 as conference proceedings and 1 in book series during 2006-15. The top 15 journals together accounted for 170 publications (31.72\% share of the India's output) during 2006-15, which decreased from $40.0 \%$ to $28.79 \%$ from $2006-10$ to $2011-15$. The largest number of publications (25) had appeared in Indian Journal of Pediatrics, followed by Indian Journal of Medical Research (23 papers), Indian Pediatrics (16 papers), BMJ Case Reports (15 papers), etc during 2006-15 (Table 9).

\section{High Cited Papers}

The top 13 highly cited papers (constituting 1 conference paper, 3 reviews and 9 articles) on "Vitamin D Deficiency" have received citations from 50 to 479 (11 papers in citation range 50-97 and 2 papers in citation range 236-479) and together have received 1535 citations, with an average citations per paper of 118.08 . Of the 13 highly cited papers, 2 involved single institution participation and 11 involved multi-institutional participation ( 5 national collaborative and 6 internationally collaborative). These 13 highly cited papers involve 100 authors and 60 organizations (including 19 Indian organizations). Among Indian organizations, 2 papers each has been published by Indraprastha Appollo Hospital, Delhi and All India Institute of Medical Sciences, New Delhi and 1 paper each by 17 other Indian organizations. These 13 high cited papers are published in 11 journals, including 2 papers in Osteoporosis International and American Journal of Clinical Nutrition, and one paper each Archives of Osteoporosis, Bioorganic \& Medicinal Chemistry, Best Practice \& Research in Clinical Rheumatology, British Journal of Clinical Nutrition, Clinical Endocrinology, European Journal of Clinical Nutrition, Journal of Experimental Botany and World Journal of Gastroenterology. 
Table 8: Scientometric Profile of Top 15 Authors on "Vitamin D Deficiency" during 2006-15

\begin{tabular}{cccccccc}
\hline Name of Author & Affiliation of the author & TP & TC & ACPP & HI & ICP & \%ICP \\
\hline N.Gupta & AIIMS-New Delhi & 26 & 391 & 15.04 & 10 & 5 & 19.23 \\
A.V.Khadikar & Jehangir Hospital, Pune & 19 & 129 & 6.79 & 8 & 12 & 63.16 \\
R.K.Marwah & INMAS-Delhi & 17 & 294 & 17.29 & 9 & 1 & 5.88 \\
R.Goswami & AIIMS-New Delhi & 14 & 308 & 22.00 & 9 & 0 & 0.00 \\
N.Tandon & AIIMS-New Delhi & 13 & 333 & 25.62 & 9 & 1 & 7.69 \\
V. Sreenivas & AIIMS-New Delhi & 12 & 138 & 11.50 & 7 & 1 & 8.33 \\
C.V.Harinaryan & VIMS-Tirupati & 10 & 251 & 25.10 & 7 & 1 & 10.00 \\
A.Mithal & IAH-Delhi & 10 & 880 & 88.00 & 7 & 4 & 40.00 \\
V.Bhatia & SGPGIMS-Lucknow & 10 & 144 & 14.40 & 5 & 0 & 0.00 \\
S.C.Arya & Parmanand Hospital, Delhi & 9 & 11 & 1.22 & 2 & 0 & 0.00 \\
N.Agarwal & Parmanand Hospital, Delhi & 8 & 11 & 1.38 & 2 & 0 & 0.00 \\
T.V.Paul & CMC-Vellore & 8 & 32 & 4.00 & 2 & 0 & 0.00 \\
M.K.Garg & INMAS-Delhi & 7 & 70 & 10.00 & 5 & 0 & 0.00 \\
R.Khadgawat & AIIMS-New Delhi & 7 & 56 & 8.00 & 5 & 1 & 14.29 \\
S K. Bhadada & PGIMER-Chandigarh & 7 & 21 & 3.00 & 3 & 2 & 28.57 \\
& Total of 15 authors & 177 & 3069 & 17.34 & 90 & 28 & 15.82 \\
& Total of India & 536 & 4410 & & & &
\end{tabular}

TP=Total Papers; TC=Total Citations; ACPP=Average Citation Per Paper; ICP=International Collaborative Papers; HI=h-index.

\begin{tabular}{cccc} 
Table 9: List of Most Productive Journals Publishing India's Output on “Vitamin D Deficiency" \\
during 2006-15 & \multicolumn{3}{l}{ Number of Papers } \\
\hline Name of the Journal & 2006-10 & 2011-15 & 2006-15 \\
\cline { 2 - 5 } Indian Journal of Pediatrics & 11 & 14 & 25 \\
Indian Journal of Medical Research & 12 & 11 & 23 \\
Indian Pediatrics & 6 & 10 & 16 \\
BMJ Case Reports & 1 & 14 & 15 \\
Journal of Association of Physicians of India & 6 & 7 & 13 \\
Journal of Clinical \& Diagnostic Research & 0 & 10 & 10 \\
Endocrine Practice & 4 & 4 & 8 \\
Indian Journal of Pharma \& Bio Sciences & 0 & 8 & 8 \\
European Journal of Clinical Nutrition & 4 & 4 & 8 \\
British Journal of Nutrition & 3 & 5 & 8 \\
Clinical Endocrinology & 3 & 5 & 8 \\
Annals of Indian Academy of Neurology & 0 & 7 & 7 \\
Journal of Postgraduate Medicine & 5 & 2 & 7 \\
Archives of Osteoporosis & 1 & 6 & 7 \\
J\&K Science & 0 & 7 & 7 \\
Total of 15 journals & 56 & 114 & 170 \\
India's total output & 140 & 396 & 536 \\
Share of 15 journals output in India's output & 40 & 28.79 & 31.72 \\
\hline
\end{tabular}

\section{SUMMARY \& CONCLUSION}

The world and Indian publications on "Vitamin D Deficiency" consisted of 16672 and 536 publications during 2006-15, increasing from 807 and 10 in 2006 to 2098 and 103 publications in 2015, witnessing annual average growth rates of $11.83 \%$ and $37.08 \%$ during $2006-15$. The global publications on "Vitamin D Deficiency" came from several countries, of which the top 10 most productive countries accounted for $73.67 \%$ share of global publications and $99.22 \%$ share of global citations during 
2006-15. USA contributed the largest publication share (31.81\%), followed by U.K. (8.95\%), Italy (5.10\%), Australia, Germany, Canada and France (from $4.18 \%$ to $4.94 \%$ ), Spain, India and Turkey (from $2.88 \%$ to 3.47\%) during 2006-15. The global publication share increased in Turkey, India Spain, Australia, Germany, as against decrease in USA, Italy, U.K., Canada and France from 2006-10 to 2011-15. India's global publication share was $3.21 \%$ during 2006-15, which increased from $2.46 \%$ in $2006-10$ to $3.61 \%$ in $2011-15$. Among the total Indian publications on "Vitamin D Deficiency", $66.87 \%$ were cited 1 or more times during 2006-15. The top $0.37 \%$ (2) publications (received citations. 100 citations) contributed $16.21 \%$ citation share, top $2.24 \%$ (12) publications (received citations from 51 to 100) contributed $33.44 \%$ citation share, etc during 2006-15. Indian publications registered an average citation per paper of 8.30, decreasing from 8.10 to 3.71 from 2006-10 to 2011-15. The share of India's international publications on "Vitamin D Deficiency" was $15.30 \%$ during $2006-15$, which increased from $15.0 \%$ to $15.40 \%$ from 2006-10 to 2011-15. Among collaborating countries participating in India's output, U.K. contributed the largest share (39.02\%), followed by USA (34.15\%), Australia and Canada (13.41\% each), Switzerland and South Africa (8.54\% each), Germany (7.32\%), etc. Medicine, among subjects, contributed the largest publications share of $88.62 \%$, followed biochemistry, genetics \& molecular biology (22.01\%), pharmacology, toxicology \& pharmaceutics (6.53\%), nursing (6.34\%) neurosciences (2.80\%), agricultural \& biological science $(2.05 \%)$ and immunology \& microbiology (1.68\%) during 2006-15. A large number of Indian organizations and authors participated in Indian research on "Vitamin D Deficiency" during 2006-15, of which the top 15 organizations and 15 authors contributed $47.57 \%$ and $33.02 \%$ publications share and $71.45 \%$ and $69.59 \%$ citation share respectively of the Indian output and citations. The average productivity, citation per paper, h-index and share of international collaborative papers of these top 15 most productive organizations and authors were 17.0 and 11.80, 12.26 and 17.34, 6.2 and 6.0 and $15.69 \%$ and $15.82 \%$ during $2006-15$. Of the total Indian publications, 530 appeared in several journals, of which the top 15 journals contributed $31.72 \%$ share of the India's output, which decreased from $40.0 \%$ to
28.79\% from 2006-10 to 2011-15. The top 13 highly cited papers registered 50 to 479 citations, and together contributed 1535 citations, leading to the average citation per paper of 118.08 . Among the 13 highly cited papers, 2 were single institution papers, 5 national collaborative and 6 internationally collaborative and these involve 100 authors and 60 organizations (including 19 Indian organizations). The largest number of high cited papers (2 each) was contributed by Indraprastha Apollo Hospital, Delhi and All India Institute of Medical Sciences, New Delhi and 1 paper each by 17 other Indian organizations. These 13 high cited papers are published in 11 journals, including 2 papers in Osteoporosis International and American Journal of Clinical Nutrition, and one paper each by other 9 journals.

Concludes that there is a urgent need to frame a national policy in this area, undertake more $R \& D$ and recognize vitamin $D$ deficiency as a public health problem and allocate more healthcare funds in this area. Widespread prevalence of vitamin D deficiency in India is undeniable. Factually, sun exposure is an untenable solution, for most individuals in India, towards attaining vitamin D sufficiency. Low calcium intake in conjunction with vitamin D deficiency makes matters worse. The need for improvement in vitamin status of the Indian population is both important and urgent. The Indian government needs to take substantive measures in this direction. Revision of RDA for calcium and vitamin D is required. Better facilities and technologies should be made available countrywide to enable timely diagnosis of clinical manifestations of vitamin $\mathrm{D}$ deficiency in individuals who need attention by the clinicians. Population-based programs at the national level must be developed to increase awareness of the problem at hand, to provide affordable vitamin D supplements and also to provide vitamin D fortified foods to the Indian populace at large. Research in this field needs continued support to provide a comprehensive picture of the ongoing vitamin D problem and also to study and monitor the effect(s) of a partnership between the government, healthcare system, industry and consumers, aimed at improving the vitamin D status in India.

\section{ABOUT AUTHORS}

Ritu Gupta: Had completed his B.Lib. Sci. and M.Lib Sci degrees from Annamalai University and at present registered for Ph.D degree in the Department of Library \& Information Science at Sri Venkateswara University, Tirupathi, Andhra Pradesh. She has published more than 45 papers in the area of bibliometrics and scientometrics.

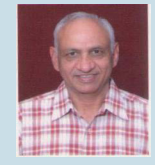

Dr B.M. Gupta: Is now a retired scientist. He was working as Emeritus Scientist in the National Institute of Science, Technology \& Development Studies (NISTADS), CSIR, New Delhi from 2008 to 2013. B.M.Gupta retired from CSIR as Scientist G in July 2008. Dr B.M.Gupta has completed B.Lib Sci from Kurukshetra University in 1971, Associatship in Documentation from INSDOC in 1975 and PhD from Karnatak University in 1999. Mr Gupta is the recipient of the Fullbright Professional Fellowship in Library \& Information Science (1999) and is elected the Fellow of the Society for Information Science (2007). Dr Gupta has more than 200 research papers mainly in the area of scientometricst, which are published in learned national and international journals.

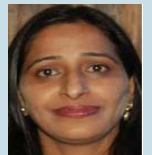

Kiran Baidwan: Is Senior Library \& Information Assistant at the Dr. Tulsi Das Library, PGIMER, Chandigarh. She graduated in B.Sc Non- medical and B.Lib. Sc., then post graduated in M.Lib.Sc and Sociology with Diploma in Computer Application.

Jeevanjyot Kaur: Is Senior Library \& Information Assistant at the Dr. Tulsi Das Library, PGIMER, Chandigarh. She graduated in B.Sc medical and B.Lib. Sc., then post graduated in M.Lib.Sc and Public Administration with post graduate course in Information technology (PGCIT). 


\section{REFERENCES}

1. Ritu G and Gupta A. Vitamin D Deficiency in India: Prevalence, Causalities and Interventions. Nutrition. 2014;6(2):729-75.

2. Hari Kumar KVS, Aravinda K, Kalra S. Scientometric analysis of endocrinology research from India. Journal of Scientometric Research. 2013;2(2):132-36.

3. Bhutani, Garima, Jyoti K and Sushila G. Bibliometric analysis of Indian Journal of Endocrinology and Metabolism. Indian Journal of Endocrinology \& Metabo- lism. 2013: 17(5):871-5.

4. Kumar KH, Aravinda K. Trends in endocrinology related research articles in medical journal from India. Indian Journal of Endocrinology \& Metabolism. 2012;16(6):931-4.

5. Bharadwaj RK and Ram S. Mapping of Indian research in osteoporsis. Annals of Library \& Information Studies. 2013;60(4):276-83. 